\title{
A CLÍNICA DO ACOMPANHAMENTO TERAPÊUTICO COMO PESQUISA PSICANALIITICA: UMA ESCRITA COMPARTILHADA ENTRE VÁRIOS
}

\author{
Analice de lima Palombini; LoRenNa Pinheiro Rocha
}

Analice de Lima Palombini

Universidade Federal

do Rio Grande do Sul

(UFRGS), Professora do

Instituto de Psicologia,

Programa de Pós-

Graduação em

Psicologia Social e

Institucional, Porto

Alegre/RS, Brasil.

Lorenna Pinheiro

Rocha

Universidade Federal

do Rio Grande do Sul

(UFRGS), Mestre pelo

Instituto de Psicologia,

Programa de Pós-

Graduação em

Psicologia Social e

Institucional, Porto

Alegre/RS, Brasil.

\begin{abstract}
RESUMO: O presente trabalho aborda a temática do método clínico na pesquisa em psicanálise, a partir da experiência de atendimento de um adolescente desde a perspectiva do Acompanhamento Terapêutico (AT). Tomando a pesquisa em psicanálise como uma produção marcada pela indissociabilidade entre saber teórico e prática clínica, discutiremos o método da construção do caso clínico, entendida como uma fiç̧ão produzida pelo encontro que a clínica promove. Apresentaremos, nesse contexto, a experimentação de uma "escrita compartilhada" com o adolescente acompanhado, abrindo a possibilidade de que ele escreva, reescreva e ressignifique a sua própria história, produzindo, assim, novos sentidos para si.
\end{abstract}

Palavras-chave: método clínico; pesquisa em psicanálise; Acompanhamento Terapêutico; adolescência.

ABSTRACT: The Therapeutic Accompaniment clinic as a psychoanalytic research: a shared writing between several. This paper introduces the subjectmatter of the clinical method in psychoanalytic research, discussing the treatment experience of a teenager boy by the perspective of the Therapeutic Accompaniment (TA). Taking research in psychoanalysis as a production marked by the integration between theoretical knowledge and clinical practice, we discuss the method of construction of the case, understood as a fiction produced by the encounter that clinical promotes. We will present, in this context, the trial of a "writing shared" with the accompanied teenager, opening the possibility for him to write, rewrite and reframe his own history, thereby producing new meanings for himself.

Keywords: clinical method; research in psychoanalysis; Therapeutic Accompaniment; adolescence.

DOI - http://dx.doi.org/10.1590/S1516-14982017003012 
Eu não procuro, acho, isto quer dizer que, no campo de Freud, basta a gente se abaixar para colher o que há para achar.

Jacques $\operatorname{Lacan}^{1}$.

$\mathrm{N}$ uma época em que nos vemos confrontados com a ascensão da ideologia cientificista, trazendo como marca os diagnósticos que se baseiam em sistemas classificatórios, agrupando sintomas em categorias nosográficas - sintomas esses muitas vezes silenciados pela tendência à medicalização -, a utilização de um método que dá lugar à fala do sujeito sobre seu sofrimento funciona como forte instrumento de crítica a posicionamentos que esvaziam a subjetividade (RUDGE, 2012).

Essa discussão, no entanto, não é recente; o próprio surgimento da psicanálise representou a possibilidade de um desvio no caminho da objetificação característica da ciência moderna. Nesse contexto, Freud (1909/2006) já alertava, como resposta às críticas de que a sua teoria não se configurava como uma ciência aos moldes que the eram exigidos e à cobrança por uma comprovação da eficácia do seu método, que "a psicanálise não é uma investigação científica imparcial, mas uma medida terapêutica. Sua essência não é provar nada, mas simplesmente alterar alguma coisa" (p. 97)².

É com base nessa concepção que realizamos uma pesquisa de mestrado - que deu origem a este trabalho -, cujo objetivo consiste em investigar as contribuições do dispositivo do Acompanhamento Terapêutico (AT) à clínica psicanalítica da adolescência no campo da Saúde Mental. Para tanto, utilizamos o método clínico, a partir do acompanhamento de um adolescente ligado a um serviço de saúde do município de Porto Alegre.

Partindo deste caso, apresentaremos, aqui, a proposta que desenvolvemos e experienciamos de uma escrita compartilhada ${ }^{3}$ com o adolescente - e também com outros atores que se fizeram presentes no processo: a orientadora da pesquisa e integrantes do projeto de extensão que nos serviu de campo de investigação, além dos profissionais dos serviços envolvidos no cuidado ao jovem em questão. Nessa escrita compartilhada, entrelaçam-se - como via de resistência a um modo objetalizado de relação - trechos das produções do adolescente durante o acompanhamento e a narrativa que construímos para compor seu caso clínico.

Esse compartilhamento do espaço de autoria do que se produz a partir do caso apresenta-se, a nosso ver, em consonância com o papel de destaque que é conferido ao método clínico numa pesquisa em psicanálise, justamente por incluir o sujeito no campo de sua própria experiência; retirando-o, portanto, da condição de exclusão na qual a ciência o colocou. Tomaremos, então, nesse contexto, a palavra e o desenho do adolescente como corpo do texto que se produz a partir do seu acompanhamento, mantendo, assim, o compartilhamento de lugares e experiências - seu quarto, sua casa, nossas vivências, mas também o espaço em branco das folhas de papel - que só tornou-se possível por sua disponibilidade em aventurar-se conosco nesta jornada.

\section{UMA PASSAGEM OBSTRUÍDA - O CASO CLÍNICO dE MARCOS}

Iniciaremos pelo recorte do caso clínico de $\mathrm{Marcos}^{4}$ - rapaz que, durante pouco mais de um ano, acompanhamos, desde a perspectiva do AT, no contexto do projeto ATnaRede 5 . Salientamos, como já

${ }^{1}$ Lacan, 1964/1988, p. 211.

${ }^{2}$ Apesar da conhecida filiação de Freud ao projeto fisicalista de Ernst Mach - que, através da redução do universo a um complexo de sensações, professava a ideia da continuidade da física à psicologia (ASSOUN, 1981/1983) - e, portanto, ao cientificismo de sua época, a invenção mesma da psicanálise vinha transgredir esse ideal, o que Freud não deixava de reconhecer.

${ }^{3}$ A grafia do termo será justificada mais adiante.

${ }^{4}$ Nome fictício.

${ }^{5}$ O Projeto Acompanhamento Terapêutico na Rede Pública (ATnaRede), ligado ao Instituto de Psicologia da UFRGS desde 1998, opera como projeto de ensino, pesquisa e extensão em torno da prática do AT. Em parceria com serviços de assistência social, saúde e justiça do município, acolhe demandas oriundas de tais serviços, com os quais mantém uma interlocução, abrindo espaço para a construção em rede dos casos propostos para AT. O projeto é composto por estagiários de psicologia, extensionistas, residentes em saúde mental coletiva e mestrandos de psicologia e áreas afins. 
anunciado, que as produções de Marcos também comporão esta escrita, o que buscaremos justificar na seção sobre a escrita compartilhada que desenvolvemos. Cabe enfatizar, porém, que, embora partamos de uma concepção de interpretação que, como nos alerta Lacan (1954-1955/1985), não se trata de revelar algo que já estaria dado, pronto para ser captado, mas que surge no momento em que o sujeito, ao nomeá-lo, dá existência a algo que não estava posto de antemão, tais produções não serão utilizadas como objetos de análise e, sim, tomadas como produto e testemunho desse encontro.

Para tanto, nesta construção, inspiramo-nos em Cidades invisíveis, de Ítalo Calvino (1972). Nesse romance, que parte de personagens reais da história, o autor extrapola os fatos possíveis e cria um diálogo entre Marco Polo, viajante encarregado de descrever, ao imperador Kublai Khan, as 55 cidades por onde teria passado, já que o imperador, apesar de ser dono do infinito império que as abrangia, não tinha o privilégio de conhecer o território dominado. Calvino, então, constrói seu texto intercalando os relatos do viajante com a própria história contada pelo narrador. Seguiremos essa mesma proposta, mesclando os escritos e desenhos do acompanhado com e por entre os nossos, mas sem a intenção de explicá-los, considerando que, como afirma Marco Polo, "jamais se deve confundir uma cidade com o discurso que a descreve" (CALVINO, 1972, p. 2).

Meu nome é Marcos. Eu estudei no ***. la de ônibus para lá, mas não gostava, era apertado e cheio. Era uma escola especial, uma classe terapêutica. Parei de estudar há cinco anos, porque mexiam comigo lá. Eu gosto de comer guisado, tomate e batata. Não gosto de galinha. Eu pegava os ônibus Clemente e São Jorge para ir à escola quando a minha mãe me levava, naquela época. Eu tomo banho todo dia; passo sabonete e shampoo. Eu sou alegre, sorridente, adolescente, bem educado e bem simpático. Gosto de bater papo com a minha psicóloga e de ver TV também. Eu não gosto de sair porque tenho vergonha de pegar ônibus lotado ${ }^{6}$.

Marcos é um rapaz de 19 anos que há quatro não sai de casa. Permanece a maior parte do dia em seu quarto, ocupando o tempo com a televisão. A equipe que o acompanha propôs o AT na tentativa de estabelecer uma via de contato com ele, a quem diagnosticam dentro do espectro do autismo.

Entre o lugar de "doente", que ocupa na família, e a infantilização, que se dá a ver em seus desenhos, passando para o real do corpo por meio de sua voz, forçadamente aguda e difícil de ser diferenciada entre masculina ou feminina, - marcando, assim, alguma recusa ou tentativa de apagamento da diferenciação sexual -, Marcos se percebe e se diz criança; e é como se apresenta a nós no início do AT.

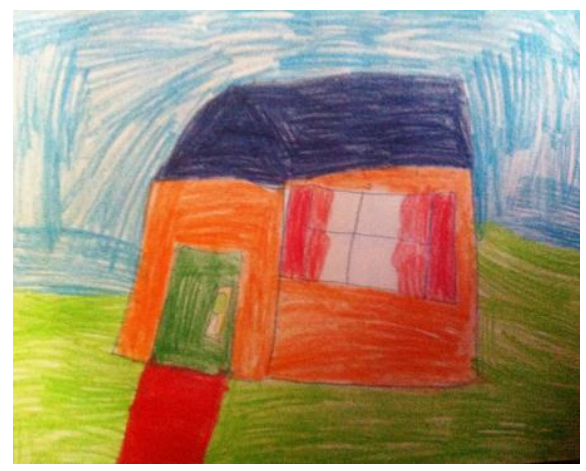

A dificuldade de sair de

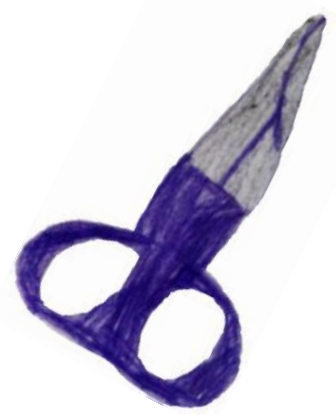
casa, principal motivo que levou ao encaminhamento do caso para o AT, revela uma impossibilidade mesma de realizar a operação psíquica, inerente à adolescência, de passagem do espaço privado da família em direção ao público da cidade - entendida, aqui, como local de produção de relações, de conflitos e de negociações, que não se esquiva diante da friç̧ão dos encontros (PECHMAN, 20057). Essa passagem parece obstruída pelo que Palombini (2002) nomeia de hipertrofia do corpo materno ${ }^{8}$,"o qual apenas foi capaz de suportar uma experimentação dos espaços sociais por parte do filho, enquanto tomados como extensão de si mesmo (extensão do

Conta com um espaço semanal de supervisão na universidade e prevê a participação em reuniões de rede e com as equipes dos serviços parceiros (PALOMBINI, 2008).

${ }^{6}$ Os textos de Marcos, aqui reproduzidos, aparecem em ordem cronológica de sua produção, tendo o primeiro sido escrito num momento em que já vínhamos trabalhando juntos há cerca de seis meses.

${ }^{7}$ Uma versão do artigo de Pechman (não publicado) em que nos baseamos encontra-se em PECHMAN; MEDEIROS, 2005.

${ }^{8}$ Enquanto espaço primevo em que um bebê adquire existência psíquica e do qual, posteriormente, deve-se diferenciar para, então, explorar o que se encontra para além do corpo que lhe deu origem. 
corpo materno) e não como expressão de uma diferença" (PALOMBINI, 2002, p. 3). Desse modo, tudo o que ultrapassa esse campo é tomado como amedrontador, já que a inscrição simbólica da diferença entre mãe e filho não pôde efetuar-se.

Esse posicionamento de resistência a tudo que está fora dos contornos de sua casa, no entanto, não é exclusivo de Marcos, apesar de, nele, mostrar-se mais cristalizado. Por várias ocasiões, a mãe reclama das brincadeiras do outro filho, de 12 anos de idade, que gosta de jogar futebol e de andar de bicicleta na rua com os amigos, ainda que ele se mantenha sempre pela vizinhança. Ela é taxativa ao dizer-lhe que deve "ir de casa para o colégio e do colégio para casa". Poderíamos acrescentar, aqui, o modo como se estabelece a transferência dessa mãe conosco: ela prepara as comidas de que gostamos, organiza, no nosso aniversário, uma festa, à semelhança das que prepara para os filhos, e sempre afirma que já fazemos parte da família. Em várias situações, tende a nos colocar no lugar de filha mais velha. Parece ser a maneira pela qual ela consegue sustentar a presença, em sua casa, de alguém que vem de fora - mas também, e diante da ameaça que a nossa presença representa ao continuum que se estabelece entre mãe e filho, diríamos que ela, ao nos incorporar como objeto de seus cuidados, tenta apagar as possibilidades de uma confrontação do filho com o Outro sexo (PALOMBINI, 2002). Desse modo, nesse

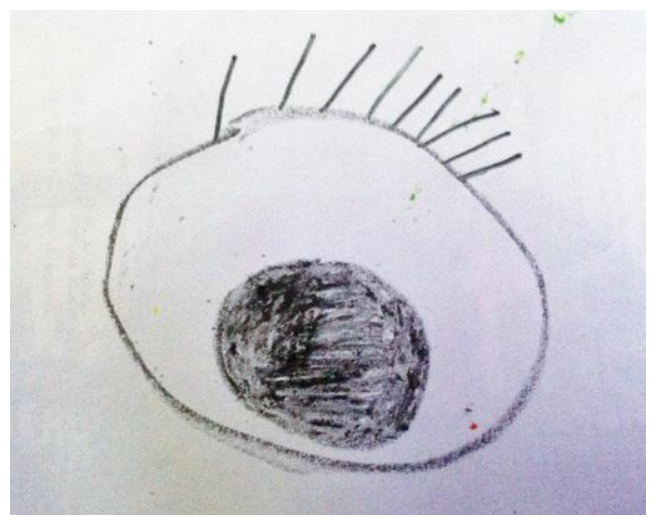
acompanhamento, considerando a dinâmica familiar que toma o "lado de fora do portão" como um local a ser evitado, e servindo a casa, nesse contexto, como uma defesa diante das fantasias construídas em torno aos perigos provenientes dos espaços públicos, seria preciso, primeiramente, ocupar o quarto, a sala, a cozinha, explorando novas possibilidades e lugares psíquicos, para, só então, nos aventurarmos na geografia da cidade.

O desenrolar dos encontros parece ir operando uma mudança na posição subjetiva de Marcos. Ele começa a reclamar de certas atitudes da mãe e, até mesmo, a confrontá-la. Para nós, em segredo, confidencia: "Ela não é mais a mesma pessoa".

Rassial (1999) pontua que a adolescência corresponde a um momento em que a mãe, na qualidade de Mãe primordial, que dá lugar a outras encarnações possíveis do Outro, vem a ser interrogada. Ela é, portanto, recolocada em cena e em questão quanto ao seu estatuto. Nesse sentido, a afirmação de Marcos parece dar testemunho de que alguma separação está se fazendo operar: ao questionar o lugar da mãe, ele se desloca da posição de objeto de gozo do Outro materno, numa tentativa de articulação da cadeia de significantes que o constitui. Nesse sentido, ele é que parece não ser mais a mesma pessoa, já que, agora, consegue perceber que, a esse Outro - antes absoluto, onipotente -, falta alguma coisa, possibilitando, assim, a emergência de um desejo seu.

Outro ponto que merece ser ressaltado diz respeito ao fato de que, contrariando o diagnóstico estabelecido pela equipe de saúde (do qual discordamos desde os primeiros encontros ${ }^{9}$ ), Marcos não demonstra dificuldade em fazer laço conosco. Desde o início, mostra-se bastante receptivo à proposta do AT, mesmo sabendo que, para isso, teria de conviver com a presença de outras pessoas no espaço íntimo do seu quarto. Com o decorrer do acompanhamento, indícios de uma transferência erótica começam a se estabelecer: ele diz sentir nossa falta, elogia nossa aparência, nosso sorriso e o perfume do shampoo que usamos, beija nossas mãos e nos abraça. Perguntanos se o achamos bonito e nos pede fotos de biquíni na praia. Ao desejar-nos

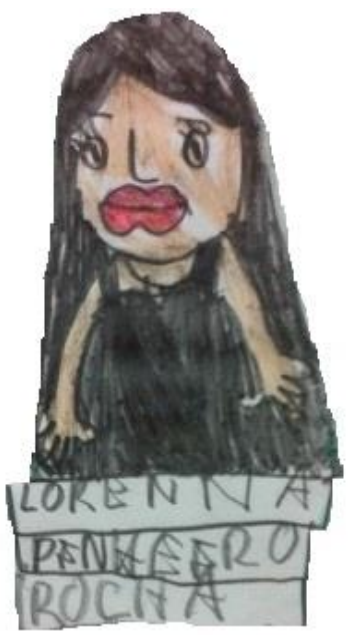

${ }^{9}$ Depois de, aproximadamente, seis meses desde o início do acompanhamento, foi possível realizarmos uma reunião com a equipe que o encaminhou ao AT, onde pudemos questionar e desconstruir o diagnóstico de autismo, que já vinha sendo reproduzido em seu atendimento por cerca de dez anos. Em consenso, chegamos à conclusão de que se tratava de um caso de psicose. 
um feliz natal, pronuncia os votos com um ato falho, em que diz "Até que a morte nos separe" no lugar de "Um ótimo ano novo".

Tomemos esse amor transferencial como um dos motores que coloca em movimento a experiência em questão, levando em consideração que o AT não conta com as ressalvas próprias ao setting analítico, que visam à abstenção do analista diante da demanda de amor do paciente. A presença de um acompanhante no cotidiano de seu acompanhado, a proximidade física que acaba por se estabelecer entre eles, os afetos que emergem das experiências compartilhadas ao longo do trabalho exigem a invenção de formas próprias de sublimação do caráter sexual do erotismo, sem recusa ao prazer que possa advir da relação (PALOMBINI, 2009). Nesse sentido, construímos uma relação pautada no que poderíamos chamar de amizade, pensada, aqui, a partir da concepção de Nietzsche (1883, apud ARAÚJO, 2005), que toma o amigo como um terceiro, entre eu e mim, que me incita à transformação.

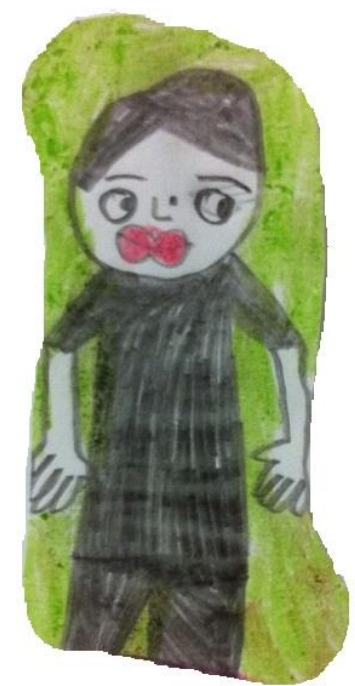

Assumimos, então, partindo dessa concepção de amizade, a posição de amigas de Marcos, o que nos possibilita sustentar uma não aceitação, mas, ao mesmo tempo, uma não recusa da demanda de amor que nos é dirigida. Vamos ocupando, assim, um lugar de terceiro termo entre mãe e filho, à medida que entramos nessa relação como aquelas a quem ele endereça e confidencia aquilo de que sua mãe não pode saber e que, portanto, cumpre o papel de marcar alguma separação com respeito ao Outro materno.

Nesse contexto, Marcos modifica o conteúdo discursivo que endereça a nós. As novelas mexicanas, que antes ocupavam um lugar central nos nossos encontros, pouco a pouco perdem a sua força e a TV, sempre ligada, ganha uma outra função: dificultar que a mãe escute aquilo sobre o que conversamos.

Percebemos, então, que Marcos passa a se dedicar, cada vez mais, ao desenho. A cada encontro, um novo mundo em traçados coloridos. Se, de início, ocupava-se apenas de objetos do seu cotidiano, como roupas, comidas e utensílios domésticos, aos poucos, suas produções tornam-se mais elaboradas e criativas, adquirindo uma outra significação para ele. Ao grafitar as contracapas dos seus álbuns de fotografias, customiza-as, à semelhança de como o fazem os jovens dos filmes e novelas que assiste. Aos poucos, a escrita, que antes era evitada, também entra em cena, nomeando todos os objetos que desenha.

Começa, então, a desenhar lugares onde gostaria de ir, paisagens, o pôr do sol e também pessoas. A elas, que são, em sua maioria, jovens mulheres, ele dá nome, sobrenome e uma história para contar. São histórias que misturam as nossas histórias individuais e a que construímos e vivemos juntos, dia a dia, lado a lado. 0 intervalo, que nossa presença faz abrir entre Marcos e sua mãe, parece alargar-se, tornando possível a entrada de outras pessoas, outras mulheres, outras relações que, mesmo fruto da sua imaginação, deixam transparecer um desejo ali em causa.

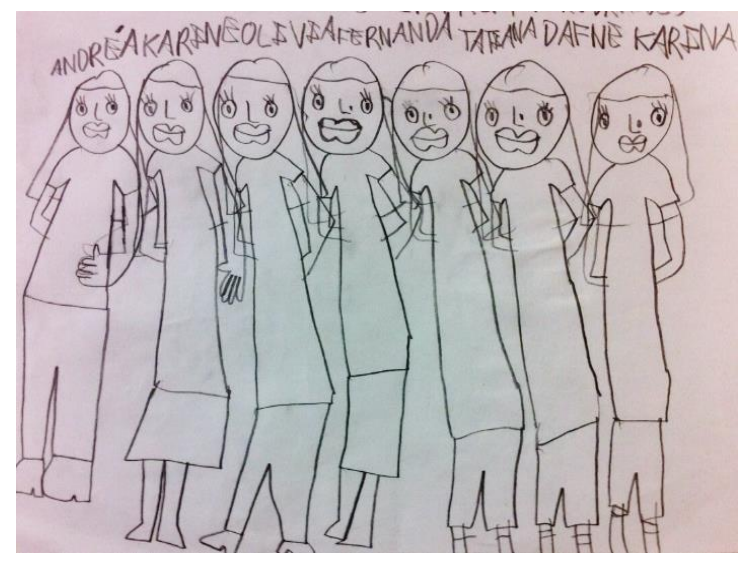

Sabrina Barros Almeida da Silva estuda, trabalha e dança. É bonita. Toma banho e é muito cheirosa. Escova os dentes. Tem bochechas grandes e olhos escuros. Toma café da manhã e vai para a escola. Tem vários amigos e adora desenhar. Ela gosta de tomar banho de piscina. Ela está olhando para a lua cheia. Eu gosto dela.

Marcos passa, então, a apresentar um maior interesse pelas coisas do "fora": pergunta onde havíamos ido durante o final de semana, o que tinha para fazer lá, como eram as árvores, se havia animais, se o ônibus estava lotado. Nesse contexto, recebemos da mãe - que não demonstra empolgação alguma ao nos contar - a notícia de que ele havia, pela primeira vez em quatro anos, saído de casa na companhia do pai. O motivo é bastante significativo, por constatar um distanciamento de sua condição infantil: o alistamento obrigatório no exército. 
Decidimos, em supervisão, que seria hora de propor uma saída, já que nos encontrávamos sufocados naquele ambiente quase asfixiante de seu quarto, sob os olhos e ouvidos vigilantes de sua mãe. Num dia bem quente de verão, convidamos Marcos para tomar um sorvete. Ele, no entanto, rapidamente, responde: "Calor? Eu estou é com frio", enquanto veste um blusão de gola alta.

Numa segunda tentativa, mais adiante no processo, ele aceita a proposta e parece animado com a ideia, mas pede que deixemos para a semana seguinte, pois precisaria pedir a permissão da mãe, que não está presente no momento. No outro encontro, a mãe veta o passeio, afirmando que as roupas de Marcos estavam curtas e que seria preciso comprar-lhe novas; constatação que, talvez, pudesse dizer de algum efeito de deslocamento nessa mãe, agora confrontada com o evidente crescimento do filho. A cada semana, uma nova desculpa, e assim seguimos por, aproximadamente, dois meses. Os encontros começam a ser desmarcados ou remarcados, e acabamos por deixar a proposta em suspenso para não inviabilizar a continuidade do AT.

Em nosso último encontro antes de encerrarmos o acompanhamento, no entanto, recebemos a notícia de que Marcos, demonstrando ter construído alguma brecha no que lhe obstruía a passagem, decidiu ir ao cabeleireiro e, em seguida, ao supermercado, pois gostaria de comprar alguns lanches para compartilharmos.

Nesse sentido, o AT - à medida que mantém sempre a possibilidade de uma circulação pela cidade no horizonte do acompanhamento, mesmo nos casos em que os encontros acontecem, prioritariamente, na residência do acompanhado - abre espaço para um deslocamento subjetivo e físico que poderia funcionar como uma metáfora da própria operação adolescente de deslocar-se do laço 5 familiar em direção ao social. Aqui, portanto, o AT parece ter surgido como um meio pelo qual Marcos pode ensaiar construir um caminho que o leve, não apenas em direção à cidade, mas ao que, nela, Ihe surge como possibilidade de vida, de apropriação de um lugar para si, tornando possível a enunciação de um desejo, originariamente, seu.

Eu gostaria de trabalhar num curso da faculdade, fazer formatura, porque ano que vem eu faço 20 anos. Ainda demora. Queria trabalhar escrevendo e desenhando. Eu gosto de desenhar, desenho bastante. Gosto de desenhar com giz de cera e com canetinha e lápis de cor. Gosto de dormir. Queria conhecer Santa Maria e Santa Rosa. É a terra da Xuxa; ela é legal, mas não trabalha mais na TV. Em alguns anos, eu gostaria de votar nas eleições de outubro de 2014. Antes, vem a copa do mundo. Eu gostaria de ir para um jogo do Brasil no Beira Rio, aqui em Porto Alegre, no Rio Grande do Sul.

\section{A ESCRITA COMPARTILHADA - UMA ESCRITA COM E ENTRE VÁRIOS}

Alicerçadas em uma perspectiva que pretende colocar em cena a relação que se estabelece entre acompanhante e acompanhado, tomando-a como força motriz do processo de AT, e no fato de que o próprio método clínico, como afirma Berlinck (2009), "se revela pela narrativa construída pelo médico e o paciente na situação analítica" (p. 441), lançamos mão da experimentação, junto com Marcos, disso que convencionamos chamar de escrita compartilhada.

A ideia foi inspirada na dimensão do pesquisarCOM, proposto por Márcia Moraes (2010), que afirma a pesquisa como uma prática performativa - por fazer surgir realidades que não estavam dadas de antemão e que não existem em nenhum outro lugar senão nas e por meio das intervenções do pesquisador - que se faz com o outro, e não sobre ou apesar dele. Tal posicionamento representa uma via possível de resistência a um modo objetalizado de relação, afirmando aquele com quem se pesquisa como participante ativo do dispositivo de intervenção, em ruptura, portanto, com uma lógica de produção de conhecimento tributária do cientificismo.

Transpondo essa concepção para a realidade de uma pesquisa que tem a clínica como seu campo de investigação por excelência, propusemos-nos a desenvolver essa escrita como forma de possibilitar que a palavra de Marcos aparecesse como parte constituinte da narrativa produzida a partir do desenrolar de seu caso. Com isso, reafirmamos e concretizamos, no próprio texto, o seu lugar: não meramente de sujeito da 
pesquisa ${ }^{10}$, mas, principalmente, de sujeito do desejo, em consonância com a ética da psicanálise.

A grafia que optamos por utilizar chama a atenção, justamente, para esse ato de escrever, que, numa pesquisa que traz, em seu cerne, o método clínico, só se faz possível com o outro. É dos efeitos das intervenções realizadas e das afetações que emergem da relação entre analista e analisante, ou, como no nosso caso, entre acompanhante e acompanhado, que o caso pode ser delineado. Além disso, com a nomenclatura utilizada, fazemos referência, também, à possibilidade de uma partilha deste espaço de produção de saber, de transmissão da experiência. Nesse sentido, partimos da concepção de que, para que não tomemos o outro com quem pesquisamos como mero alvo de intervenções e interpretações isoladas, é preciso que adotemos uma postura que nos permita pesquisar e escrever com ele, e não sobre ele (sendo a escrita compartilhada apenas uma forma, dentre tantas possíveis, de fazê-lo), abrindo espaço para que, juntos, possamos construir algo partilhável nesse encontro de saberes.

Nossa ideia inicial era propor uma participação direta e expressa do acompanhado na construção do seu caso clínico, por meio de intervenções no corpo do texto que vínhamos produzindo a partir do seu acompanhamento. E, assim, abrindo espaço tanto para a incorporação do que ele próprio considerasse dever constar ali, quanto para a exclusão de algo com o que ele não concordasse. Tal proposta, porém, foi logo abandonada. Primeiramente, para não cairmos no risco das armadilhas de uma análise selvagem, já que Marcos deparar-se-ia com interpretações para as quais talvez ainda não estivesse preparado. Também pela impossibilidade mesma de sua execução, considerando que Marcos apresentou, durante quase todo o período em que o estivemos acompanhando, grande rejeição a atividades que envolviam a escrita e a leitura. Ele, de fato, demonstrava dificuldade na construção de palavras e frases no papel. Não escrevia seus textos de punho próprio, mas ditava para que nós o fizéssemos; em seguida, relíamos juntos para que ele tivesse a opção de alterar o que julgasse necessário, o que, no entanto, nunca chegou a acontecer.

Frente a essas dificuldades, optamos por incluir em seu caso clínico o que ele vinha produzindo durante o acompanhamento ${ }^{11}$ - escritos livres sobre a sua vida, sobre o que gostaria de fazer no futuro, sobre os seus desenhos, dentre outros -, entendendo que esse seria um modo possível de mantê-lo como autor presente no texto, tomando parte desta escrita com suas palavras.

A proposta residia, portanto, em não deixar passar despercebido aquilo que ganhou consistência e permanência por meio de traçados numa folha em branco. Sustentávamo-nos na crença de que a escrita pode funcionar como um importante instrumento na clínica, por abrir a possibilidade de uma retomada do uso da palavra, de um reencontro com a linguagem (TREVISAN, 2007; MADEIRA; RICKES, 2007). O processo funciona, nesse sentido, como um meio pelo qual se pode efetuar a passagem do individual ao social, do privado ao público, do íntimo ao compartilhável, assim como propõe o AT.

Finalizando o acompanhamento, percebemos que Marcos não havia escrito um volume de textos suficiente para o propósito que havíamos pensado para eles. No entanto, já tínhamos em mãos outro tipo de escrita produzido por ele, tão potente quanto a palavra decodificada em letras e signos: seus desenhos. Para desenhar, ele não precisava de ajuda ou de "intérpretes"; era senhor de si. Segundo Costa (2010), as ilustrações produzidas por um analisante falam quando a palavra parece insuficiente para tal função, ao que Kupfer et al. (2009) acrescentam que, num processo clínico, elas podem ser tomadas como significações a serviço de uma história, de uma narrativa ou de uma informação. É o que podemos perceber no caso de Marcos: em seus desenhos, desejos, angústias e vivências são representados, outras cenas podem ser produzidas, outros espaços podem ser visitados e outras pessoas podem ser conhecidas. Tais ilustrações podem servir de testemunho - e não apenas de objeto a ser interpretado - do deslocamento subjetivo empreendido por Marcos durante o acompanhamento.

Nesse sentido, além de a escrita compartilhada trazer, em si, uma via possível de recusa às formas de assujeitamento próprias à ciência positivista, ela dá espaço a que Marcos - por entre esses escritos e desenhos produzidos no espaço que o AT lhe proporciona - escreva, reescreva e redesenhe a sua própria história. E,

${ }^{10}$ Fazendo referência à terminologia utilizada pela ciência moderna para designar aqueles que são considerados objetos de estudo numa pesquisa.

11 Salientamos que a utilização, nesta escrita, das produções de Marcos foi previamente autorizada por ele, por meio de um Termo de Consentimento Livre e Esclarecido, assinado, também, por seus responsáveis legais. 
com isso, a ressignifique, movimento que tomamos como necessário à produção de novos sentidos ${ }^{12}$.

Embora tenhamos dado ênfase, aqui, à escrita compartilhada com Marcos, não poderíamos deixar de mencionar que, como o título deste trabalho já sugere, outras mãos se fazem escrever por meio das nossas, de modo que o compartilhamento deste espaço de produção narrativa não se dá apenas entre o eixo acompanhante-acompanhado. Nossa pesquisa se inseriu num projeto de extensão que conta com um momento semanal de supervisão coletiva e mantém um diálogo constante com as equipes de referência nos casos acompanhados. Desse modo, podemos afirmar que a escrita à qual nos referimos se produz entre vários $^{13}$ - acompanhante, acompanhado (e seu entorno), orientadora e demais integrantes do projeto, além dos profissionais dos serviços.

Trabalhar com esse método num âmbito coletivo - que se materializa, como já dito, tanto nas equipes dos serviços da rede de atenção psicossocial como no grupo que compõe o projeto ATnaRede - abre espaço ao relato dos encontros, servindo, portanto, como lugar de endereçamento para a fala do sujeito da enunciação. A palavra proferida a um coletivo, que apenas pode tomar corpo num só-depois da cena clínica, permite que se confira forma àquilo que se produziu no terreno da intervenção (LIMA et al., 2013). Nesse sentido, ainda que não explícito no texto, é por meio das nossas palavras que esses outros vários podem falar, pois o que escrevemos pode ser tomado como desdobramento, também, do que escutamos; a palavra que lançamos ao grupo retorna diferente, e essa diferença aparece como matéria-prima para a escrita em questão.

Desse modo, é possível que recolhamos, não apenas da experiência clínica, mas também da própria supervisão, ou seja, desse compartilhamento de vivências que se faz num entre vários, alguns elementos que nos permitem reter algo transmissível e avaliável de cada caso.

\section{O MÉTODO CLÍNICO NA PESQUISA EM PSICANÁLISE}

A psicanálise, aqui, constitui referência ética e ferramenta conceitual que nos permite pensar o caso e propor intervenções. Nesse campo, como já apontava Freud (1912/2006; 1933[1932]/2006), saber teórico e prática clínica apresentam-se indissociáveis, sendo esta última tomada como lugar, não de aplicação de um saber, mas de produção desse saber, visto que a origem mesma da psicanálise deu-se como método de tratamento. Assim sendo, a clínica é o próprio solo que sustenta a pesquisa em psicanálise.

Uma vez que o contexto clínico é sempre singular, por dizer respeito ao que emerge da relação transferencial entre analista e analisante, a pesquisa que se pretende psicanalítica assume um caráter bastante particular no cenário da produção científica de conhecimento. De um lado, objetifica-se o sujeito com quem se pesquisa e, de outro, não se deixa de também objetificar o pesquisador, ao se prezar por uma suposta neutralidade científica, impossível numa pesquisa que trabalha com o método clínico.

Em nosso estudo, que se define, portanto, como uma pesquisa em psicanálise, a clínica que vemos entrar em cena é a clínica do AT. Tomando como norte a concepção de Fédida (1991), de que "na psicanálise, o caso é uma teoria em gérmen, uma capacidade de transformação metapsicológica" (p. 230), valemo-nos do método da construção do caso clínico para pensar os possíveis efeitos subjetivos decorrentes dos encontros proporcionados pelo AT, uma vez que a teoria psicanalítica só se faz possível a partir do que se produz na clínica.

\footnotetext{
12 Salientamos que é o próprio Marcos quem nos fornece a pista de abrirmos espaço a que ele possa escrever e reescrever a própria história. Em um de nossos primeiros encontros, durante uma conversa com a mãe em que ela me relata alguns fatos importantes da vida do rapaz, ele interfere, seja para corrigi-la ou para complementá-la, mostrando, assim, a sua versão dos acontecimentos. Tal movimento apresentou-se bastante significativo para Marcos, ao abrir a possibilidade de produção de novos sentidos para si. Daí a ideia de incorporarmos essa vontade de contar a sua história à condução do acompanhamento.

13 Tomamos de empréstimo, aqui, o termo entre vários, fazendo alusão à prática entre vários, denominação sugerida por Jacques-Alain Miller, na abertura da III Jornada da Rede Internacional de Instituições Infantis, para referir-se à modalidade de trabalho clínico realizado com crianças autistas e psicóticas em instituições como Antenne 110 e Courtil, na Bélgica. Correspondendo a uma variante da psicanálise aplicada, atualizada no contexto institucional, a prática entre vários, segundo Di Ciaccia (2005), permite pensar as particularidades da psicanálise na instituição. Em particular, as vicissitudes da transferência que envolve a relação do paciente com vários profissionais e, portanto, com vários saberes. Aqui, fazemos referência a este dispositivo, pensando no trabalho em instituições onde a psicanálise se inclui como um saber entre outros, de forma não-hierarquizada, e sustentada pela ideia de que há um impossível de saber em cada caso, exigindo que se reporte ao próprio sujeito para orientar-se na direção do seu tratamento.
} 
Esse método, segundo Fédida (1991), consiste numa "coelaboração" empreendida entre analista e analisante, que diz respeito à história ficcional produzida e - poderíamos dizer - compartilhada no encontro que a clínica promove. Mas, por que ficcional? Lacan (1962-1963/2005) nos adverte acerca da distinção que se coloca entre dois registros: "de um lado, o mundo, o lugar onde o real se comprime, e, do outro lado, a cena do Outro, onde o homem como sujeito tem de se constituir, tem de assumir um lugar como portador da fala, mas só pode portá-la numa estrutura que, por mais verídica que se afirme, é uma estrutura de fiç̧ão" (p. 130). É nesse segundo registro que uma intervenção analítica pode incidir, tornando possível a construção de um caso a partir da história ficcional que se escreve e se inscreve na relação estabelecida entre analista e analisante.

Ainda a esse respeito, em conformidade com a definição que nos oferece Lacan da transferência como "fenômeno em que estão incluídos, juntos, o sujeito e o psicanalista" (1964/1988, p. 219), podemos afirmar que a construção do caso revela não apenas o sujeito que fala do seu sofrimento, mas também o analista que o escuta e as sinuosidades do campo conceitual por onde se transita (SOUSA, 2000). Partindo dessa perspectiva, temos que a construção do caso corresponde a uma ficção produzida pelo encontro que a clínica promove e que abre possibilidade para que se inclua, na pesquisa, a dimensão da relação que se estabelece entre acompanhante e acompanhado. Assim, ambos são participantes ativos do dispositivo de intervenção, rompendo com a ideia de sujeito objetalizado da pesquisa e, também, de neutralidade do pesquisador. É essa concepção de construção do caso clínico que vem dar sustentação metodológica ao desenvolvimento da escrita compartilhada que propusemos. Nela, são também as nossas afetações mútuas - seja durante os atendimentos, seja nos momentos de supervisão ou de reunião de equipe - que dão consistência ao texto que se produz a partir do acompanhamento.

Figueiredo (2004), nessa discussão, salienta que a construção do caso clínico configura uma das mais importantes contribuições da psicanálise à psicopatologia e à saúde mental, por abrir espaço a que seja o próprio sujeito em análise o responsável por "guiar" o desenrolar do seu processo - num trabalho analítico, quem, de fato, precisa trabalhar, é o analisante. Termo por termo, a autora define "construção" como um arranjo dos elementos provenientes do discurso do paciente, visando a uma conduta, e aponta a sua finalidade como sendo a de partilhar determinados elementos de cada caso em um trabalho conjunto. Por sua vez, "caso" diz respeito ao latim cadere, que significa cair, podendo ser tomado como o produto que se extrai das intervenções do analista e daquilo que é decantado do relato do sujeito em análise. Por fim, "clínico", partindo do grego kline (leito), faz referência ao ato de debruçar-se sobre o leito de um paciente e, a partir daí, produzir um saber. Por "construção do caso clínico", portanto, devemos compreender um "(re)arranjo dos elementos do discurso do sujeito que 'caem', se depositam com base em nossa inclinação para colhê-los, não ao pé do leito, mas ao pé da letra" (FIGUEIREDO, 2004, p. 79).

Tomando como referência o caso clínico discutido, não se trata nem da história de Marcos, nem do relato que elaboramos a partir dessa história, mas de uma construção que toma como base os elementos recolhidos do seu discurso e as produções decorrentes da elaboração em análise - incluindo-se, aí, tanto os escritos e desenhos de Marcos como as intervenções realizadas e os efeitos que, delas, advieram -, visando traçar o caso a partir daquilo que decanta da sua história.

A construção de um caso clínico, portanto, corresponde a uma leitura que só se faz possível nesse espaço terceiro que analista e analisante compartilham. Ela não opera de forma a desvelar um objeto já existente, mas trabalha de forma inventiva. É o retroagir de um traço sobre outro que viabiliza a criação de um novo sentido para a cadeia significante, à medida que possibilita novas configurações dos elementos em questão (SIMONI; RICKES, 2008). Nessa zona intervalar em que podemos desenhar um mais além, nem dentro nem fora e, ao mesmo tempo, dentro e fora - como o trabalho do AT (ROLNIK, 1997) -, emergem a experiência e a transmissão de um saber que, nela, se produz como resultante de uma afetação mútua entre heterogêneos que ganha contornos próprios pelo trabalho de pesquisa.

Tal método não corresponde ao mero efeito de um saber sobre um sujeito que conta a sua história, com fins a produzir conhecimento, mas dá sustentação a que esse sujeito produza um saber que lhe é próprio. Assim, trabalhamos com o método clínico, não numa perspectiva de tomar o acompanhamento realizado como espaço de "manipulações experimentais" de uma nova modalidade interventiva, nem de objetificar em categorias os possíveis efeitos decorrentes desse acompanhamento, mas como via que se abre para que, sustentados pela ética da psicanálise, ou seja, pela ética do desejo, pudéssemos incluir o adolescente acompanhado como participante ativo do dispositivo de intervenção e, portanto, da própria pesquisa. 


\section{PARA FINALIZAR...}

O método clínico diz de um esforço de diagnóstico e de tratamento de um sujeito - e, reforçamos, não de uma doença -, independente da especificidade do campo do saber de onde provenha o profissional que lance mão de sua utilização. Não raro, no entanto, sua legitimidade é defendida com base na concepção de que ele corresponderia à aplicação do método científico na prática diagnóstica e terapêutica, o que, segundo Rudge (2012), "redunda em atrelar sua dignidade à que se confere à ciência", como podemos obsevar nas tentativas atuais de interligar a psicanálise às neurociências, espaços de produção distintos por natureza.

No campo psicanalítico, onde pesquisa e intervenção coincidem, o método clínico é revisitado e reatualizado a cada novo caso que se constrói, impossibilitando, assim, que sua definição seja atrelada à mera aplicação de um saber teórico a uma prática clínica. Nesse sentido, ela difere de uma concepção de saber que se produz aprioristicamente, sem levar em consideração as especificidades do sujeito que se the apresenta. Nesse campo, só podemos pensar num saber que se funda, pela via do inconsciente, num a posteriori, abrindo espaço, assim, por meio do método clínico, para a inclusão do analisante no processo de pesquisa.

No tocante à nossa experiência, lançamos mão de uma construção coletiva, produzida e compartilhada em meio a uma polifonia de saberes, que toma como base não um sujeito-objeto de estudo, mas o sujeito Marcos em sua singularidade e autoria. Com base no que construímos juntos durante o acompanhamento, buscamos, por meio da escrita compartilhada, dar lugar a que ele produzisse um saber que lhe fosse próprio, e esse posicionamento - que vai na direção de uma escuta singular - parece-nos abrir espaço para a produção de efeitos de significação num sujeito que, engendrado pela cultura, pode transcender o lugar em que é colocado e apontar na direção de seu desejo, abrindo possibilidades para a produção de um caso e, na melhor das hipóteses, de um novo sujeito.

Recebido em: 12 de janeiro de 2016. Aprovado em: 28 de junho de 2016.

\section{REFERÊNCIAS}

ARAÚJO, F. Um passeio esquizo pelo acompanhamento terapêutico: dos especialismos clínicos à política da amizade. Dissertação de Mestrado, Programa de Pós-Graduação em Estudos da Subjetividade, Universidade Federal Fluminense. Niterói, 2005.

ASSOUN, P. L. Introdução à epistemologia freudiana (1981). Rio de Janeiro: Imago, 1983.

BERLINCK, M. T. O método clínico: fundamento da psicopatologia. Revista Latinoamericana de Psicopatologia Fundamental. V. 12, n. 3, 2009, p. 441-444. São Paulo: Editora Escuta.

CALVINO, I. Cidades invisíveis. São Paulo: Biblioteca Folha, 1972.

COSTA, T. Psicanálise com crianças. 3. ed. Coleção passo-a-passo. Rio de Janeiro: Zahar, 2010.

DI CIACCIA, A. A prática entre vários. In: LIMA, M. M.; ALTOÉ, S. (orgs.). Psicanálise, clínica e instituição. Rio de Janeiro: Rios Ambiciosos, 2005.

FÉDIDA, P. Nome, figura e memória - a linguagem na situação psicanalítica. São Paulo: Editora Escuta, 1991.

FIGUEIREDO, A. C. A construção do caso clínico: uma contribuição da psicanálise à psicopatologia e à saúde mental. Revista Latinoamericana de Psicopatologia Fundamental. V. 7, n. 1, 2004, p. 75-86. São Paulo: Editora Escuta.

FREUD, S. Análise de uma fobia em um menino de cinco anos (1909) Rio de Janeiro: Imago, 2006. (Ed. standard brasileira das obras completas, 10).

Conferência XXXIV - Explicações, aplicações e orientações (1933[1932]) Rio de Janeiro: Imago, 2006. (Ed. standard brasileira das obras completas, 22).

Recomendações aos médicos que exercem psicanálise (1912) Rio de Janeiro: Imago, 2006. (Ed. standard brasileira das obras completas, 12 ).

KUPFER, M. C. M. et al. (2009). Valor preditivo de indicadores clínicos de risco para o desenvolvimento infantil: um estudo a partir da teoria psicanalítica. Revista Latinoamericana de Psicopatologia Fundamental. V. 6, n. 1, 2009, p. 48-68. São Paulo: Editora Escuta.

LACAN, J. A angústia (1962-1963). Rio de Janeiro: Jorge Zahar, 2005. (O seminário, 10). 


\section{A clínica do Acompanhamento Terapêutico como pesquisa psicanalítica:}

\section{uma escrita compartilhada entre vários}

O eu na teoria de Freud e na técnica da psicanálise (1954-1955). Rio de Janeiro: Jorge Zahar 1985. (O seminário, 2).

seminário, 11).

Os quatro conceitos fundamentais da psicanálise (1964). Rio de Janeiro: Jorge Zahar, 1988. (O

LIMA, M. C. P. et al. (2013). Arte e mediação terapêutica: sobre um dispositivo com adolescentes na clínica-escola. Revista Mal-Estar e Subjetividade. V . 13, n. 3-4, 2013, p. 775-796. Fortaleza: Universidade de Fortaleza.

MADEIRA, M.; RICKES, S. Pedrital Hospinstante. In: Comissão de Aperiódicos da Associação Psicanalítica de Porto Alegre. (org.). Psicose: aberturas da clínica. Porto Alegre: APPOA, 2007.

MORAES, M. PesquisarCOM: política ontológica e deficiência visual. In: MORAES, M.; KASTRUP, V. (orgs.). Exercícios de ver e não ver: arte e pesquisa com pessoas com deficiência visual. Rio de Janeiro: Nau Editora, 2010

PALOMBINI, A. L. Passagens obstruídas: quartos privativos, mínimas janelas. Revista da Associação Psicanalítica de Porto Alegre: Clínica da Adolescência, n. 23, 2002, p. 63-68. Porto Alegre: APPOA.

Programa de Acompanhamento Terapêutico na Rede Pública: um projeto de ensino, pesquisa e extensão [Mimeo]. Universidade Federal do Rio Grande do sul, Porto Alegre, 2008.

Utópicas cidades de nossas andanças: flânerie e amizade no Acompanhamento Terapêutico. Fractal: Revista de Psicologia, v. 21, n. 2, 2009. Niterói: EdUFF, p. 295-318.

PECHMAN, R. M. Quando Hannah Arendt vai à cidade e encontra com Rubem Fonseca, ou da cidade, da violência e da política. In: ; MEDEIROS, S. A. A cidadela dos indivíduos. Psicologia, clínica e cultura. V. 17, 2005, p. 123-135. Rio de Janeiro.

RASSIAL, J-J. O adolescente e o psicanalista. Rio de Janeiro: Companhia de Freud, 1999.

RINALDI, D. L.; ALBERTI, S. (2009). Psicanálise, saúde mental e universidade. Estudos e Pesquisas em Psicologia. N. 9, 2009, p. 533-545. Rio de Janeiro: UERJ.

ROLNIK, S. Clínica nômade. In: Equipe de Acompanhantes Terapêuticos do Hospital-Dia A Casa (orgs.). Crise e cidade: acompanhamento terapêutico. São Paulo: EDUC, 1997.

RUDGE, A. M. Método clínico, ciência e subjetividade. Revista Latinoamericana de Psicopatologia Fundundamental. V. 15, n. 2, 2012, p. 235-239. São Paulo: Editora Escuta.

SIMONI, A. C. R.; RICKES, S. M. Do (des)encontro como método. Currículo sem Fronteiras. V. 8, n. 2 2008, p. 97-113.

SOUSA, E. L. A. A vida entre parênteses: o caso clínico como ficção. Psicologia Clínica. V. 12, n. 1, 2000, p. 11-19. Rio de Janeiro: PUC-Rio.

TREVISAN, E. Atelier de escrita: um lugar possível de endereçamento. In: Comissão de Aperiódicos da Associação Psicanalítica de Porto Alegre. (org.). Psicose: aberturas da clínica. Porto Alegre: APPOA, 2007.

Analice de Lima Palombini

analice.palombini@gmail.com

Lorenna Pinheiro Rocha

lorennapinheiro@hotmail.com 